\title{
The Changing of the Guard in Academia and Academic Research Leadership_Employing Natural Language Processing
}

\author{
Eyal Eckhaus ${ }^{1} \&$ Nitza Davidovitch ${ }^{2}$ \\ ${ }^{1}$ Department of Economics and Business Administration, Ariel University, Ariel, Israel \\ ${ }^{2}$ Head of Academic Quality and Assessment, Head of Teacher Training Program, Ariel University, Israel \\ Correspondence: Eyal Eckhaus, Department of Economics and Business Administration, Ariel University, Ariel, \\ Israel.
}

Received: March 18, 2020

Accepted: April 24, 2020

Online Published: July 23, 2020

doi:10.5539/ies.v13n8p95

URL: https://doi.org/10.5539/ies.v13n8p95

\begin{abstract}
This pioneering study examines the meaning of academic leadership in terms of the changing of the guard in academia. Research findings on seniority and experience and their association with leadership show that these have a considerable impact on management skills and on the ability of those with experience and seniority to influence the young leadership. This is particularly essential in academia where research is the most meaningful and effective value that serves as a measure of faculty members. Management skills are not perceived as a coherent part of faculty members' work.

Structural Equation Modeling confirmed the developed model. Findings show that indeed, from the perspective of faculty at the academic institution, senior experienced faculty members undoubtedly contribute to the academic institution first of all in research, but also otherwise. Senior and experienced faculty members contribute by encouraging, directing, and guiding young faculty members on how to contribute to the institution, particularly through the activity which is expected of them as academic faculty - i.e., research. This urging and direction is one of the most well-known qualities in the context of academic leadership - the ability to help people develop, advance, and to outline a high-quality academic research tradition. The meaning of the findings is that senior faculty has a contribution beyond their direct output in the form of scientific publications, as a research engine and spotlight for the young faculty. Notably, no difference was found in faculty's perception of this contribution of senior faculty members by gender or age.
\end{abstract}

Keywords: retirement, research leadership, academia, academic faculty, pension

\section{Introduction}

The transformational leader (TL) was defined as one who serves as a role model for followers, demonstrates an ability to motivate, inspire, and stimulate followers to be creative and innovative (Eckhaus, 2016). This leadership style has been described as a preferred leadership style (ibid.). TL may be formed in different organizations, including academia. Leadership is a key issue for universities and is increasingly regarded as beneficial to improved performance across all activities, including research (Ball, 2007). While research is one of the most dominant roles in academia, how to handle challenges in the academic system is also part of the process of advancing and even surviving in the system. A leader who can help push new faculty in the right direction may ease their assimilation in the system and help them understand how to better reach achievements.

\section{1 "Leading in Academia"-Vanguard of Academic Leadership}

In 2019 the Council for Higher Education (CHE), together with the Edmond de Rothschild Foundation, developed the "Leading in academia" program that set itself a goal of being a vanguard of academic leadership (CHE website).

The "Leading in academia" program is intended for outstanding senior academics and administrators and aimed at providing them with the necessary tools and skills for becoming integrated in senior leadership posts in academia, such as presidents and vice presidents, rectors, and CEOs. The reasons that led to development of the program:

- The growth rate of Israel's academic institutions, side by side with the technological challenges involved in teaching and research, require future academic managers to cope with changing academic worlds. 
- At present, the institutions are managed by senior academics whose main occupation and training is in research and teaching and not necessarily academic management and leadership.

Prof. Yaffa Zilbershats, Chair of the Planning and Budgeting Committee (PBC), says that academic excellence also means managerial excellence. The new program will locate outstanding researchers and administrators in the medium ranks, impart management tools, and create a vanguard that will generate change and lead the system of higher education to new heights in the fields of research, management, and student advancement.

The vision of the program (as written in the CHE decision) relates to building a prospective impact group of "change agents" from all academic institutions in Israel that will act to promote an outstanding, learning, and innovative system that anticipates the future in order to promote research, the students, and the rules of the industry". "Leading in academia" is a joint program of the Council for Higher Education, the Edmond de Rothschild Foundation, and the Partnerships organization.

\subsection{On the Uniqueness of the Academic Leadership}

Israel's institutions of higher education are managed by senior academics whose main occupation and training is in the field of research and teaching and not necessarily in the field of academic management and leadership. Nevertheless, by virtue of their jobs, academic managers are required to provide a daily response to a range of significant strategic topics and issues such as setting goals, priorities, planning, managing people, regulation, and more.

Moreover, the growth rate of academic institutions in Israel, side by side with additional challenges such as openness to the international sphere, increasing interdisciplinary interfaces in teaching and research within and outside the institutions, the dominance of the hi-tech industry, and expected sociodemographic changes, are presenting Israel's system of higher education with an accelerated process of change. Coping with the changing reality requires the next generation of academic managers to acquire a toolbox adapted to the changing academic worlds. Leaders of the program in the CHE and at the Edmond de Rothschild Foundation believe that the new training will enable the vanguard to see the full picture and to learn from that achieved in top institutions around the world.

\subsection{Academic Leadership in Research and Teaching}

"A leader is created but must also be born", said Rudolph Guiliani, former Mayor of New York, and this is also the motto of Erez Levy, manager of the supply chain in the solar division of Applied Materials and chairman of Israel's Council of Supply Chain Management. In his lectures to students, he devotes an entire session to the topic of leadership and its various features. "Leadership can be learned, taught, developed, and improved" (Levy, 2020).

Is this relevant for academic management? Can faculty members, of whom the expected activity is research and the products required and for which they are judged are research products, contribute to promotion of academic leadership as well, and if so - how?

There are many studies on leadership. Some relate to leadership as an acquired skill, namely, leadership is not perceived as a congenital trait (such that "either you are born with it or not..."). Leadership can be learned, taught, developed, and improved. Leadership develops throughout one's life and is learned in several ways:

The first is by observing other leaders and imitating behaviors: The figure of the leader can be that of a dominant colleague or manager in one's workplace.

The second is through life experience: Events in our life "compel" us to express, and even develop, our leadership capabilities.

In the current study we have chosen to focus on recent and relevant research on recognizing the benefits of prior management training and experience, as well as seniority, following transition to a second career in the education and teaching professions.

Shperling (2015) is similar in its characteristics to those of the academic system that deals with research and teaching-where teaching means imparting research skills. The review discusses the issue of the potential contribution of prior management experience and training in various organizations to management skills in the educational system. The review covers similar and unsimilar management skills characteristic of managers in different organizations such as the military and hi-tech firms, as well as management skills necessary for working in education and teaching.

The review indicates that, as a rule, prior training and experience in management in organizations that have a different organizational and managerial culture than that of the educational system can have a positive impact, from many aspects, on the management of the educational system, for instance in management skills of 
self-criticism, creativity, self-efficacy, coping with uncertainty, coping with discipline, and lack of motivation by students, promoting values, striving for excellence, creating leadership, and experiential and meaningful learning. These multiple aspects might further establish the call to recognize the value and benefit of training and of prior management experience for skills required for management of the educational system.

The purpose of this review is to examine the recognition of prior managerial experience and seniority of those who served in the army for many years and of those who worked in hi-tech firms for a lengthy period and then transferred to the field of education and teaching (Shperling, 2015). The review indicates the uniqueness of academic leadership.

\subsection{The Contribution of Experience and Training to Management of Teaching}

Studies indicate that teachers with effective classroom management have a greater influence on the study progress of their students than ineffective teachers. Effective management may be attributed to prior experience and management training. Prior experience and training can affect various aspects of education (Marzano, Marzano, \& Pickering, 2003). For example:

1) Self-inquiry, self-criticism, and learning from mistakes - Prior experience in a system that has a culture of self-inquiry, self-criticism, and learning from mistakes, such as an in the army, can also help the self-evaluation process of teachers and its internalization as a routine daily process. Moreover, proper treatment of mistakes and mutual learning from them leads to improvement of the organization's outcomes and has economic results as well (Linder-Ganz \& Shtrakman, 2016). An example of this is evident in the words of Major General (res.) Eyal Hofman, principal of the Beit Ekstein Tom high school in Givataim, in a study that examined the role of military debriefing in the management style of formerly military principals. He said that creativity, thinking outside the box, and directing each student to the best course, is only part of what the educational system should emphasize. Even more important, and severely lacking in the system, is self-criticism. In the Air Force this is a component that is a daily milestone in the life of every pilot (Yaakov-Yitzhaki, 2017).

Use of the debriefing practice, for instance, was found to not only serve organizational learning but rather also to constitute a tool for improving the status of teaching staff - principals - who seek to introduce a new management option.

This skill of self-inquiry, self-criticism, and learning from mistakes is a foundation stone of academic research and academic leadership.

2) Creativity and thinking outside the box - Management experience in a large organization or hi-tech firm is often an opportunity for thinking outside the box and raises the need to provide creative solutions for various problems that arise in one's work (Yaakov-Yitzhaki, 2017). Creativity and thinking outside the box generate a study challenge and interest and can influence the quality of the teaching process as well as the students.

This skill of creativity and thinking outside the box is the motivation for academic research, and academic leadership is capable of enhancing and supporting this fundamental element.

3) Self-efficacy - Reexperiencing successes and fulfilling various tasks in one's previous career before the teaching profession enhances teachers' perceptions of their ability to cope with challenges in teaching, i.e., perceptions concerning their self-efficacy. High self-efficacy generates a higher sense of gratification and contributes to best advancement of processes (Troesch \& Bauer, 2017).

This skill of self-efficacy is essential in academia (Davidovitch, 2004) and academic leadership is capable of helping students with this fundamental element.

4) Coping with a changing reality and uncertainty - Management skills in the army are a complex capability. They are implemented in a changing and dynamic context, one that is unexpected and uncertain. At times they are combative and at others peace-seeking and involve enlisting diplomatic strategies. In this respect they analyze the motivations and intentions of different actors and build suitable relationships for many features of the educational system and for working with children and teens, which is characterized by complexity and uncertainty (Weinberger, 2016).

Coping with a changing reality and with uncertainty is the grounds on which academic research operates, and academic leadership is capable of boosting and supporting students operating in this sphere, where every research path taken means challenging activity in practice, characterized by uncertainty.

5) Coping with student discipline when learning - Prior management experience in a setting characterized by strict discipline, for instance in the army, might contribute to classroom management skills. Nevertheless, it is 
notable that this is not an unequivocal finding. Interviews with managers who served in the army for many years showed that this experience does not necessarily contribute to better coping with student discipline, compared to the unexperienced (ibid.).

Coping with student discipline in academic learning is the essence of academic discipline.

6) Emphasis on values - In academia we deal with values of protecting intellectual property, integrity, trust. Academic leadership is capable of enhancing these foundations in a world of information overload.

7) Striving for excellence - Managers who come to the educational system from large organizations and from hi-tech firms bring with them an outlook that strives for excellence and that does not make do with mediocrity. This outlook also involves high self-demands and setting a high standard for the team (ibid.). This outlook is desirable for classroom management in particular and for school management in general, particularly in an era of measurement and accountability within this system.

In academia, excellence and striving for excellence are an important value. Academic leadership is capable of enhancing these fundamental elements, while strictly maintaining academic values.

8) Experiential learning and meaningful learning - The personal experience of those who worked in other systems and organizations before joining the educational system facilitates exposure to many personal stories and a daring capacity. These contribute to learning experiences and free more resources for meaningful learning. Examples of such learning experiences: learning statistics by shooting hoops and analyzing misses and trials; designing dresses with an emphasis on parabolas; learning trigonometry on the roof of the Azrieli Towers (ibid.). Personal stories and experiential learning facilitate greater motivation in teaching and thus advance class goals in particular and school goals in general. This capability is a foundation stone of management.

Hence, despite the special characteristics of management skills in the educational system, prior experience and training in management in organizations and firms with a different culture has a positive influence on the educational system from many aspects. These positive impacts might further establish the call to recognize the value and benefit of prior management experience and training for the management skills of teachers and school principals. The following section seeks to complement this finding by means of research literature that examines the perceptions of principals in the educational system who had prior jobs in different organizations (mainly in the army) as well as the effectiveness of their management.

In academia, academic leadership is capable of influencing and outlining a path for experiential and meaningful learning.

In summary, this review supports the idea of developing and promoting academic leadership of those with prior experience and seniority in academia. The findings of the research review indicate that recognizing the importing of prior management experience, management tools, and training, for the management skills necessary in the educational system, but this recognition and its desirable scope must be examined side by side with the complexity characteristic of those who choose teaching as a second career and are required to deal with other circumstances that do not enable specific implementation of these tools.

Research hypotheses

H1. Expressions regarding older faculty's contributions positively affect expressions regarding younger faculty.

H2. Expressions regarding older faculty's contributions positively affect expressions regarding research.

H3. Expressions regarding older faculty's contributions positively affect expressions regarding the academic system.

H4. Expressions regarding younger faculty positively affect expressions regarding the academic system.

H5. Expressions regarding younger faculty positively affect expressions regarding research.

\section{Method}

\subsection{Initial Sample}

Respondents were asked to freely express their opinion on the retirement age in five different questions, which include the advantages and disadvantages of retirement age restriction, the advantages older faculty, the desire to continue working after retirement age, what can be done to facilitate this, and personal opinion on the matter.

The questionnaires were in Hebrew and they were distributed online to the senior faculty members of Ariel University, Israel, using Google Docs. One hundred and seven completed questionnaires were collected. Of all 
respondents, $47.6 \%$ were females and $52.4 \%$ males. The age range of the respondents was 36-49 (36.6\%), 50-60 $(32.3 \%)$, and 61-84 (31.2\%). Respondents were from 17 different departments, ranging from one to 17 respondents each.

We employed a mixed methods research, which enables the strengths of both qualitative and empirical methods to complement each other (Davidovitch \& Eckhaus, 2019a, 2019b).

\subsection{Analysis}

Structural Equation Modeling (SEM) was used to test the model's goodness-of-fit (Eckhaus, 2019; Eckhaus \& Davidovitch, 2019a). Model fit was estimated using TLI, CFI, RMSEA, and CMIN/DF (Cheng, Wong, \& Koh, 2016). CMIN/DF ratio should be $<2$ (ibid). $>0.90$ cutoff values indicate acceptable fit for CFI and TLI, values $<.08$ for RMSEA (de la Fuente et al., 2018).

\subsection{Text Analysis}

For text analysis we used TEXTIMUS 1.0, a software designed for text mining and analysis (Eckhaus \& Ben-Hador, 2019). The software includes features for Natural Language Processing (NLP), sentiment analysis, and latent themes discovery.

First, we generated n-gram frequencies. N-gram is a basic concept in NLP, widely used for language modeling (He, Huang, Bai, \& Bai, 2019). N-gram refers to a contiguous sequence of $n$ words from a given sequence of text (Davidovitch \& Eckhaus, 2018).

Next, we used the Bag-of-Words (BoW) technique (Eckhaus \& Davidovitch, 2018a, 2018b). According to BoW, a set of keywords is explored in all documents, where each keyword is assigned a value, according to whether the word appears in a document or the number of times it appears. Therefore, we analyzed the frequency of the words in the set of texts, and compiled into groups the words with the highest frequency employed for the research variables. We then summed the frequencies of the groups of words to create the variables, as follows. Enable words such as "enable", "allow". Young - words referring to the young faculty. System - words referring to the academic system, Research, and Older- referring to older faculty. Next, we generated the interaction variable EnableOlder, which is the interaction between Enable and Older, that is, the combination of both older faculty and enabling, implying the advantages of older faculty.

Gender and Age were added as typical controlled variables (Eckhaus \& Davidovitch, 2019b, 2019c) to the variable EnableOlder. Gender was coded as $1=$ male, $0=$ female.

\section{Results}

The correlations, means, and standard deviations between the research variables are presented in Table 1. Since Gender was binary coded, we present Spearman correlations.

Table 1. Correlation matrix, means, and SD

\begin{tabular}{ccccccc}
\hline & Age & Gender & EnableOlder & Young & Research & System \\
\hline Age & - & & & & & \\
Gender & .06 & - & & & & \\
EnableOlder & -.02 & -.17 & - & & & \\
Young & -.09 & -.16 & .004 & - & & \\
Research & -.15 & -.09 & $.22^{*}$ & $.29^{* *}$ & - & \\
System & .01 & $-.23^{*}$ & $.20^{*}$ & $.20^{*}$ & $.24^{*}$ & - \\
Mean & 55.18 & .52 & .18 & .45 & .66 & .65 \\
SD & 11.56 & .50 & 1.2 & .85 & .96 & 1.12 \\
\hline
\end{tabular}

$* p<.05, * * p<.01$.

Figure 1 illustrates the model and standardized coefficients. 


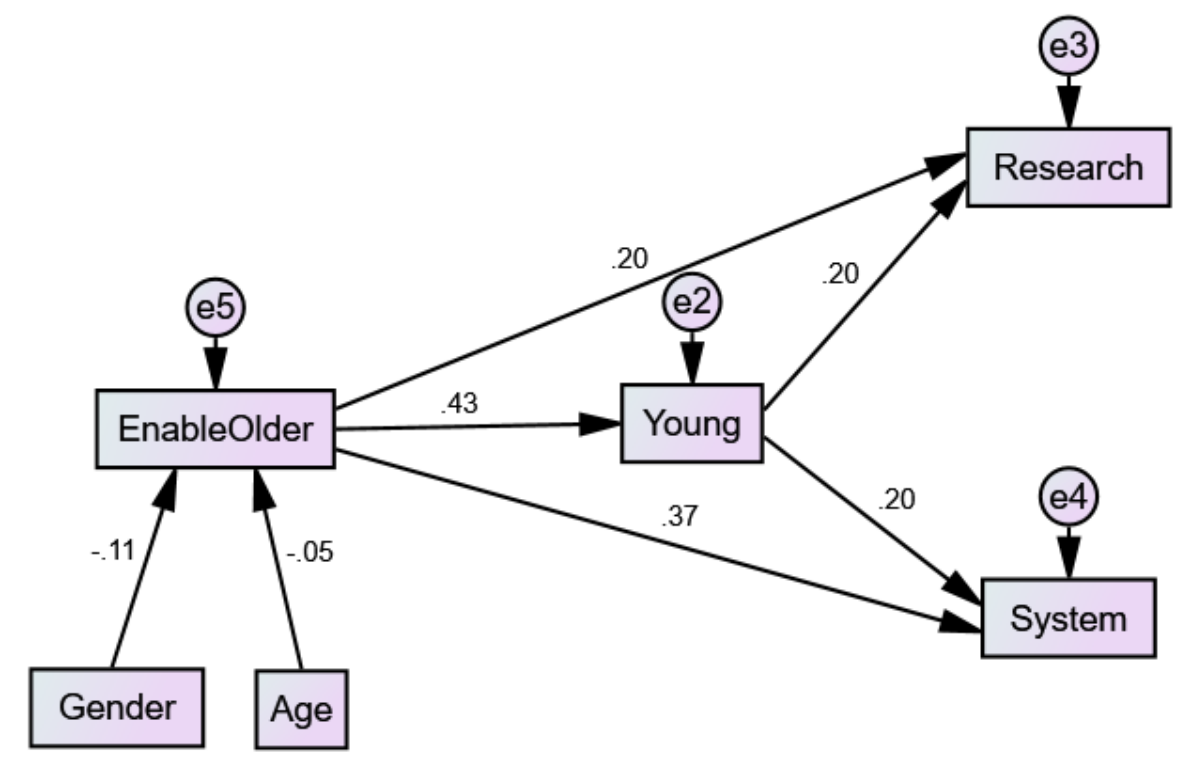

Figure 1. Model and standardized coefficients

The hypothesized model showed a good fit: $\mathrm{CMIN} / \mathrm{DF}=1.22, \mathrm{p}>.05, \mathrm{CFI}=0.97, \mathrm{TLI}=0.92, \mathrm{RMSEA}=0.05$. All hypotheses were supported. EnableOlder positively affects Young $(\mathrm{H} 1)(\beta=.43, \mathrm{p}<.001)$. EnableOlder positively affects Research $(\mathrm{H} 2)(\beta=.21, \mathrm{p}<.05)$. EnableOlder positively affects System $(\mathrm{H} 3)(\beta=.37, \mathrm{p}<.001)$. Young positively affects System (H4) $(\beta=.20, \mathrm{p}<.05)$ and Research $(\mathrm{H} 5)(\beta=.21, \mathrm{p}<.05)$.

Age and gender had no statistically significant effect on EnableOlder.

\section{Discussion and Conclusion}

The findings of the current study indicate that as perceived by faculty, older faculty contributes to the establishment first of all through research but not only. Older faculty also contributes by urging, directing, and guiding younger faculty on how to contribute to the establishment, particularly through research. Namely, older faculty has an indirect contribution beyond their direct output through publications, by pushing forward the junior faculty.

A leader in an organization is a figure who advances the organization not only by means of action-related decisions and strategic planning but rather also by urging the staff forward and directing it to benefit the organization which feeling successful, progressing, integrated in the organization, and important to it.

The power of an academic institution is based primarily on its research achievements and its ability to create breakthroughs in the scientific world. Hence, research leadership is one that supports young faculty members and directs them to improve their research capabilities. A cyclic process exists, where in time younger faculty become mature, experienced, and capable, until the time comes to assume the role of directing, guiding, and in fact becoming part of the research leadership. Nevertheless, the issue of unwilling retirement is questionable, as when one reaches an expert level of research leadership he or she can clearly fulfill an important role for the organization. We suggest that alternative options for retirement be explored, options that will concentrate on guidance jobs, which will enable the research leadership to continue. Namely, people will only retire from roles in the organization while making room for a new generation, but the latter will be able to continue relying on figures of authority to guide their way.

The findings of the research raise the need to reassess the retirement age issue, due to the vast research experience as well as research leadership capabilities that the senior faculty gained. Academic research requires experience, and it takes years for cultivating the younger faculty members' research skills, and growing a new generating that can represent the institution with their research capabilities. Seniority is an essential key to reach these results. The research domain is about human thinking development, which typically requires time. When results are finally reached, instead of being retired, the knowledge gained should be further exploited.

\section{References}

Ball, S. (2007). Leadership of academics in research. Educational Management Administration \& Leadership, 35(4), 449-477. https://doi.org/10.1177/1741143207081058 
Cheng, K., Wong, W., \& Koh, C. (2016). Unmet needs mediate the relationship between symptoms and quality of life in breast cancer survivors. Supportive Care in Cancer, 24(5), 2025-2033. https://doi.org/10.1007/s00520-015-2994-0

Davidovitch, N., \& Eckhaus, E. (2018). The influence of birth country on selection of conference destination-employing natural language processing. Higher Education Studies, 8(2), 92-96. https://doi.org/10.5539/hes.v8n2p92

Davidovitch, N., \& Eckhaus, E. (2019a). Student evaluation of lecturers-what do faculty members think about the damage caused by teaching surveys? Higher Education Studies, 9(3), 12-21. https://doi.org/10.5539/hes.v9n3p12

Davidovitch, N., \& Eckhaus, E. (2019b). Teaching students to think-faculty recommendations for teaching evaluations employing automated content analysis. International Journal of Higher Education, 8(3), 83-93. https://doi.org/10.5430/ijhe.v8n3p83

De la Fuente, J., Cabello, M., Levola, J., Caballero, F. F., Ayuso-Mateos, J. L., \& Pitkänen, T. (2018). Validity of the PARADISE24 questionnaire in people with substance use disorders: A measure to assess psychosocial difficulties. Drug and Alcohol Dependence, 187, 66-71. https://doi.org/10.1016/j.drugalcdep.2018.02.012

Eckhaus, E. (2016). Corporate transformational leadership's effect on financial performance. Journal of Leadership, Accountability and Ethics, 13(1), 90-102.

Eckhaus, E. (2019). How to be Happy. Retrieved from http://www.artistila.com/how-to-by-happy/

Eckhaus, E., \& Ben-Hador, B. (2019). Gossip and gender differences: A content analysis approach. Journal of Gender Studies, 28(1), 97-108. https://doi.org/10.1080/09589236.2017.1411789

Eckhaus, E., \& Davidovitch, N. (2018a). Impact of gender and conference size on conference preferences-employing natural language processing. International Journal of Educational Methodology, 4(1), 45-52. https://doi.org/10.12973/ijem.4.1.45

Eckhaus, E., \& Davidovitch, N. (2018b). Improving academic conferences-criticism and suggestions utilizing natural language processing. European Journal of Educational Research, 7(3), 445-450. https://doi.org/10.12973/eu-jer.7.3.445

Eckhaus, E., \& Davidovitch, N. (2019a). Effect of personal and occupational characteristics on attitudes to an obligatory retirement age-a content analysis investigation. Journal of Education and Learning, 8(6), 169-179. https://doi.org/10.5539/jel.v8n6p169

Eckhaus, E., \& Davidovitch, N. (2019b). How do academic faculty members perceive the effect of teaching surveys completed by students on appointment and promotion processes at academic institutions? A case study. International Journal of Higher Education, 8(1), 171-180. https://doi.org/10.5430/ijhe.v8n1p171

Eckhaus, E., \& Davidovitch, N. (2019c). Potential for blocking advancement: Teaching surveys for student evaluation of lecturers. International Journal of Educational Methodology, 5(3), 401-406. https://doi.org/10.12973/ijem.5.3.401

He, X., Huang, T., Bai, S., \& Bai, X. (2019). View N-gram network for 3D cbject retrieval. Paper presented at the Proceedings of the IEEE International Conference on Computer Vision. https://doi.org/10.1109/ICCV.2019.00761

Levy, L (2020). Chairman of the Council of Supply Chain Management, Manager at Applied Materials. Retrieved from http://www.adar-yoz.net/?CategoryID=166\&ArticleID=132

Linder-Ganz, R., \& Shtarkman, R. (January 8, 2016). Forget what you thought about Air Force pilots. TheMarker. Retrieved from https://www.themarker.com/markerweek/1.2817488-

Marzano, R. J, Marzano, J. S., \& Pickering, D. J. (2003). Classroom management that works. Alexandria, VA: Association for Supervision and Curriculum Development.

Marzano, R. J., Waters, T., \& McNulty, B. A. (2005). School leadership that works: From research to results. Alexandria, VA: ASCD.

Ministry of Education. (2016). Regulations for education service workers. Jerusalem: Ministry of Education. Retrieved from http://cms.education.gov.il/EducationCMS/Units/Sherut/Takanon/Perek1B/Darga/Veek/ Vetek_male.htm

Ministry of Education. (2018). Education workers portal: Seniority. Jerusalem: Ministry of Education. Retrieved 
from http://cms.education.gov.il/EducationCMS/Units/Sherut/Takanon/Perek1B/Darga/Ve

Ran, A. (2016). Reflection: Reflective and undermining thinking in education. L. Yosefsberg Ben-Yehoshua (Ed.). Tel Aviv: Mofet Institute. Retrieved from http://library.macam.ac.il/study/pdf_files/d12284.pdf

Shahar, H., \& Magen-Nagar, N. (2010). Participation in decision-making and teachers' sense of autonomy and satisfaction: Differences between schools with school-based management and schools without school-based management. Studies in Educational Management and Organization, 31, 243-269.

Shperling, D. (2015). Teacher dropout around the world: Information review. L. Yosefsberg Ben-Yehoshua (Ed.). Tel Aviv: Mofet Institute. Retrieved from http://meyda.education.gov.il/files/staj/NeshiratMorimBerachavey Haolam.pdf

Troesch, L. M., \& Bauer, C. E. (2017). Second career teachers: Job satisfaction, job stress, and the role of self-efficacy. Teaching and Teacher Education, 67, 389-398. https://doi.org/10.1016/j.tate.2017.07.006

Weinberger, Y. (2016). Education in an era of uncertainty. Tel Aviv: Resling.

Yaakov-Yitzhaki, M. (August 31, 2017). Flying to school. Yisrael Hayom. Retrieved from http://www.israelhayom.co.il/article/501117

\section{Copyrights}

Copyright for this article is retained by the author(s), with first publication rights granted to the journal.

This is an open-access article distributed under the terms and conditions of the Creative Commons Attribution license (http://creativecommons.org/licenses/by/4.0/). 